\title{
Specification for the Reattachment of the EC South Cryostat Heads
}

Engineering Note \# 3740.224-EN-322

Issued: August 1, 1991

Originator: Rick Luther 
$R D L-8 / 1 / 91$

\section{Specification for Reattachment of the EC South Crysotat Heads}

Engineering Note 3740.214-EN-322

\section{INTRODUCTION}

This Engineering Note defines technical requirements and the scope of work for reattachment of the heads of the South EC cryostat. This work is to be done in the clean room at the D-Zero Assembly Building (DAB) at Fermilab.and is expected to begin around September 15,. 1991. The task consists primarily of welding four heads onto a 17-foot diameter stainless steel double-wall pressure/vacuum vessel. Nominal thicknesses of the welds are all 5/8". Root passes are to be made by TIG welding and the balance by MIG welding. No radiography is required; other NDE per ASME Code, Section VIII, Div. 1. All work is to be done in accordance with the Rules of the National Board of Boiler and Pressure Vessel Inspectors (ANSI/NB-23), and repairs to the inner vessel are to be documented by the R-1 form executed by the Contractor's Authorized Inspector. The Contractor will be expected to work two shifts per day, five days per week to support the Fermilab schedule.

Details of the cryostat are given on Fermilab Drawings 3740.220-ME-222256, Rev. $R$, 3740.224-ME-273071, and 3740.224-ME-273039. The cryostat was fabricated by Process Engineering, Inc. of Plaistow, NH in 1989-90. The heads were removed using hand-held air-arc gouging equipment. As a result the welding grooves are not straight and their widths are not uniform, In some places the width may be as wide as 1". For the purposes of quotation, the Contractor should assume a uniform weld groove as shown in Figure 1. The amount of weld metal to be deposited for this geometry is estimated to be $500 \mathrm{lbs}$. Upon completion, the final contract price will be determined by the following formula:

Final Price $=$ Contract Price $x$ (lbs of weld metal deposited/500)

Methods of determining the amount of weld metal deposited will be agreed upon before award of the contract. 


\section{SCOPE OF WORK}

\section{Inner Vessel Heads}

Fermilab to fit heads to vessel and clamp in place

Tack heads in place and TIG weld root pass (Note that this may require some jacking to equalize gaps around the circumference.)

Fit and locate bypass tube and weld

Fermilab to install and weld center tube assy

Complete welding of the PV heads (MIG)

NDE as required

Pressure Test, by Fermilab, witnessed by Contractor and his Authorized Inspector (2 days)

Leak Check and Insulate inner vessel, by Fermilab (1 week)

Outer Vessel Heads

Fermilab to fit heads and clamp to vessel (1 week)

Tack heads and TIG weld root passes (May require local jacking to equalize gaps.)

Complete welding of the heads (MIG)

Fit and weld bypass tube

NDE as necessary

Fermilab to install center tube assy (FNAL)

Final leak check by Fermilab

\section{ITEMS TO BE SUPPLIED BY CONTRACTOR}

Manpower sufficient to support 3 to 6 welders on each of two shifts per day All welding machines, leads, torches, and other welding tools and hardware

All welding rod and/or wire, consumables, gases, etc

Grinders, brushes, etc., necessary for finishing welds, NDE, etc.

\section{ITEMS TO BE SUPPLIED BY FNAL}

Cranes (including operators) and lifting equipment as necessary

Scaffolding and/or manlifts for support of Contractor personnel. Contractor to provide manpower to rearrange, re-erect, or move as required.

Electrical power

Vacuum leak checking and pneumatic pressure testing (to be witnessed by Contractor). Vacuum leaks in welds shall be repaired by the Contractor. (Leak 
testing will be by helium mass spectrometer having a sensitivity of 10E-9 std $\mathrm{cc} / \mathrm{sec}$.)

\section{TECHNICAL REQUIREMENTS}

General

All work shall be performed in accordance with the rules of the National Board Inspection Code (ANSI/NB-23). The contractor shall make all provisions for the required Authorized Inspector. The work shall be documented on Form R-1 completed in accordance with NB-23. The inner vessels of the cryostats are stamped with the ASME Code U symbol and are registered with the National Board of Boiler and Pressure Vessel Inspectors.

The cryostats are constructed entirely of type 304 stainless steel. All welding consumables shall be E308, E308L, E309, or E309L material. All welding procedures shall be compatible with liquid nitrogen service $(-320 \mathrm{~F})$.

Design Conditions

Design pressure:

Inner: +15 psig with the jacket evacuated and full vacuum with the jacket at atmospheric pressure.

Outer: Full vacuum and +15 psig.

Operating temperature $=90 \mathrm{~K}$

Cryogen: 5000 gals of liquid argon in each cryostat. (The volume of the internals is such that the 5000 gallons of liquid completely fills the inner vessel.)

Weight of internal modules $=360,000 \mathrm{lbs}$.

Fabrication and Welding

Fabrication requirements of the ASME Code (fit-up, welding, etc.) and quality consistent with vacuum/superinsulated cryogenic service shall be maintained for both vessels of the cryostat.

All welding shall be performed by welders qualified in accordance with Section IX of the ASME Code using procedures qualified in accordance with Section IX.

Radiography of welded joints is not required. Other NDE per ASME Code and Contrator procedures.

Temporary attachment welds shall be avoided wherever possible. Any such welds which are used shall be made using qualified welders, procedures, and materials. After removal of the temporary weld the vessel surfaces shall be 
restored to their original condition and visually examined for signs of pitting, cracking, contamination, etc.

Testing

Leak testing shall be performed by Fermilab personnel. However, the contractor shall be resonsible for ensuring that all welds made by him are leak tight in accordance with the following requirements.

The total leak rate for the cryostat annular space will be shown by helium mass spectrometer testing to be less than $1 \times 10^{-9} \mathrm{std}-\mathrm{cc} / \mathrm{sec}$.

The vacuum leak tests will be conducted in accordance with standard testing procedures.

The mass spectrometer used will have a minimum sensitivity of $1 \times 10^{-9}$ std$\mathrm{cc} / \mathrm{sec}$.

The gas used for the test will contain at least $10 \%$ Grade $A$ helium with the balance being dry, oil-free air or nitrogen.

Except for background noise, there shall be no indication of leakage with the mass spectrometer on the lowest scale.

The accuracy of the tests will be verified by a calibration check of the mass spectrometer before and after each test. The calibration tests will be made on the lowest scale using a calibrated helium leak.

\section{DOCUMENTATION}

Three copies of all welding procedures to be used shall be submitted for approval prior to the start of fabrication.

Three copies of the R-1 form shall be submitted upon completion of the work: 


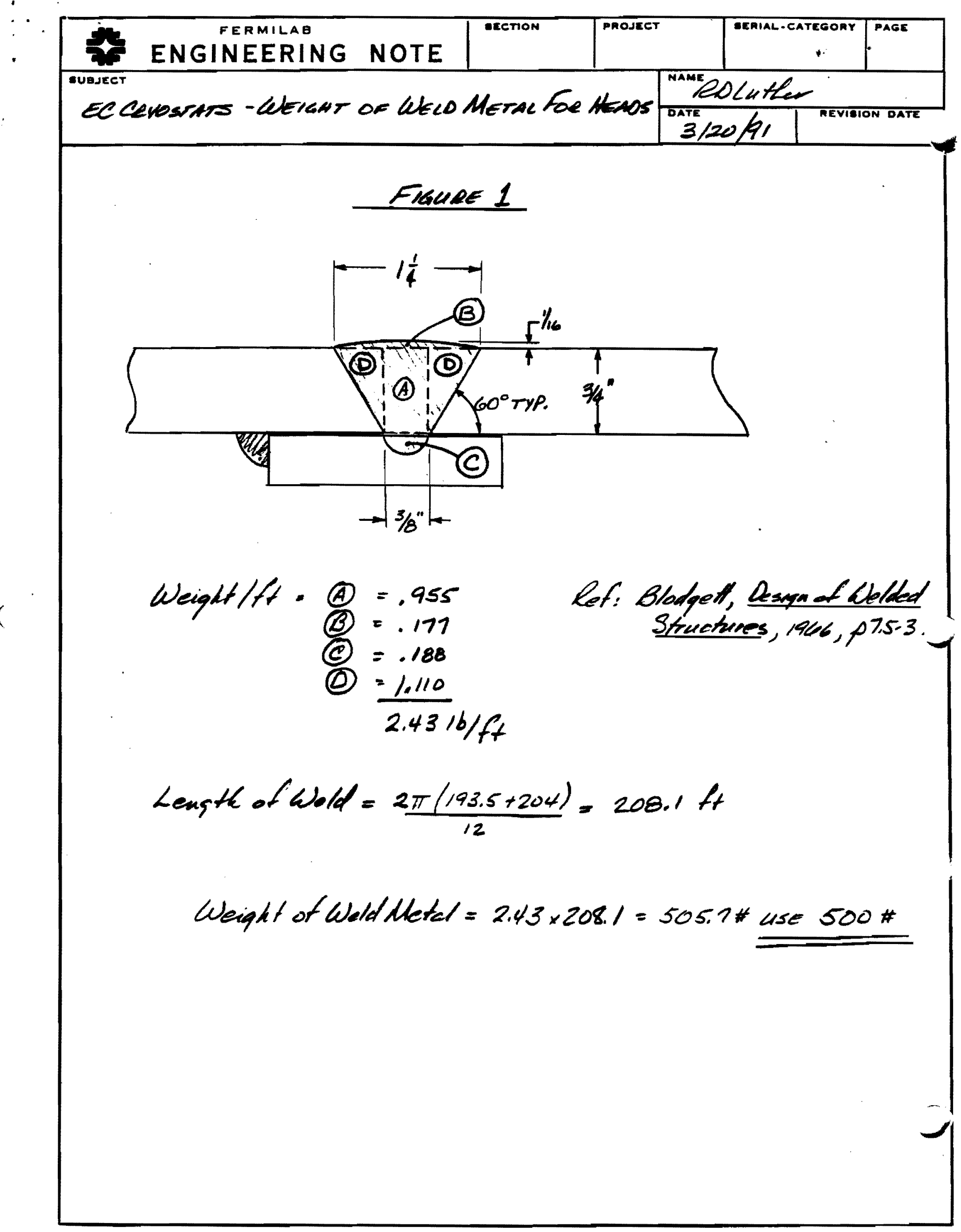

